\title{
A new species of Tangius from north India (Coleoptera, Staphylinidae, Pselaphinae)
}

\author{
Zi-Wei Yin ${ }^{1,2, \dagger}$, Li-Zhen Li ${ }^{1, \neq}$ \\ I Department of Biology, College of Life and Environmental Sciences, Shanghai Normal University, 100 Gui- \\ lin Road, Shanghai, 200234, P. R. China 2 Department of Biology, School of Life Sciences, East China Normal \\ University, 3663 North Zhongshan Road, Shanghai,200062, P. R. China \\ † http://zoobank.org/C515106C-5782-4471-AE11-483B49606A67 \\ $\ddagger$ http://zoobank.org/BBACC7AE-9B70-4536-ABBE-54183D2ABD45 \\ Corresponding author: Li-Zhen Li (lizhenli@shnu.edu.cn)
}

Academic editor: C. Majka | Received 12 September 2013 | Accepted 24 October 2013 | Published 1 November 2013

http://zoobank.org/DE447029-25C8-48CA-8F8D-09768D4641BF

Citation: Yin Z-W, Li L-Z (2013) A new species of Tangius from north India (Coleoptera, Staphylinidae, Pselaphinae). ZooKeys 346: 23-27. doi: 10.3897/zookeys.346.6233

\begin{abstract}
Tangius indicus sp. n. (Batrisitae: Batrisini) is described and illustrated from the Indian States of Meghalaya (Khasi Hills, type locality) and West Bengal (Darjeeling). Specimens of the new species are similar to those of the recently described T. glabellus Yin \& Li from Tibet, Southwest China, and can be separated only by minor differences of the male features.
\end{abstract}

\section{Keywords}

Batrisina, taxonomy, Tangius, new species

\section{Introduction}

The batrisine genus Tangius Yin \& Li (Yin et al. 2012) was recently established for a single species T. glabellus Yin \& Li, from southeast Tibet (= Xizang A. R.). Characters distinguishing it from the allied genera Dendrolasiophilus Nomura, Maajappia Nomura, and Songius Yin \& Li were described.

When visiting the Natural History Museum of Geneva, Switzerland (May, 2013), the first author sorted a small series of north Indian Tangius specimens out of the large

Copyright Zi-Wei Yin, Li-Zhen Li. This is an open access article distributed under the terms of the Creative Commons Attribution License 3.0 (CC-BY), which permits unrestricted use, distribution, and reproduction in any medium, provided the original author and source are credited. 
pselaphine collection. A second species of the genus, closely allied to T. glabellus, was recognized based on differences in male characters. In this paper we describe the new species, provide illustrations of its major diagnostic features, and distinguish it from the previously described $T$. glabellus.

\section{Material and methods}

The type series is housed in the Muséum d'histoire naturelle de la Ville de Genève, Switzerland (MHNG - G. Cuccodoro).

The collection data of the referred material are quoted verbatim. A slash (/) is used to separate different labels. Authors' notes are included in '[]'.

Measurements are in millimeters. The following abbreviations are applied: ALlength of the abdomen along the midline; AW-maximum width of the abdomen; EL-length of the elytra along the sutural line; EW-maximum width of the elytra; HL-length of the head from the anterior clypeal margin to the occipital constriction; HW-width of the head across eyes; PL-length of the pronotum along the midline; PW-maximum width of the pronotum. Length of the body equals $\mathrm{HL}+\mathrm{PL}+\mathrm{EL}+$ $\mathrm{AL}+$ length of the occipital constriction.

\section{Taxonomy}

Key to males of Tangius

1 Antennomeres VII-IX subcylindrical, as long as wide to slightly transverse (Fig. 2A); mesotibiae distinctly concave along mesal margin before preapical denticle (Fig. 2F); apex of median lobe broadly rounded on the left side (Fig. 2M). (north India: Meghalaya, West Bengal) T. indicus sp. $\mathrm{n}$.

- $\quad$ Antennomeres VII-IX asymmetrically trapezoidal, distinctly transverse (Yin et al. 2012: 59, fig. 6); mesotibiae have straight mesal margins before preapical denticle (Yin et al. 2012: 59, fig. 13; Fig. 2G); apex of median lobe angularly rounded on the left side (Fig. 2L). (Southwest China: Xizang)

T. glabellus Yin \& Li

\section{Tangius indicus Yin \& Li, sp. n.}

http://zoobank.org/49049A5A-07D6-452C-A3AA-FF5E0689E84B

http://species-id.net/wiki/Tangius_indicus

Figs 1, 2A-F, H-K, M-N

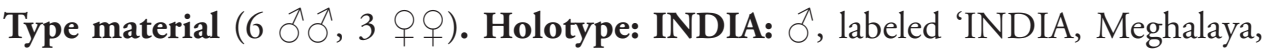
Khasi Hills, 28.X, Mawphlang, 1800 m, Besuchet-Löbl, 78. / Holotype [red], Tangius 


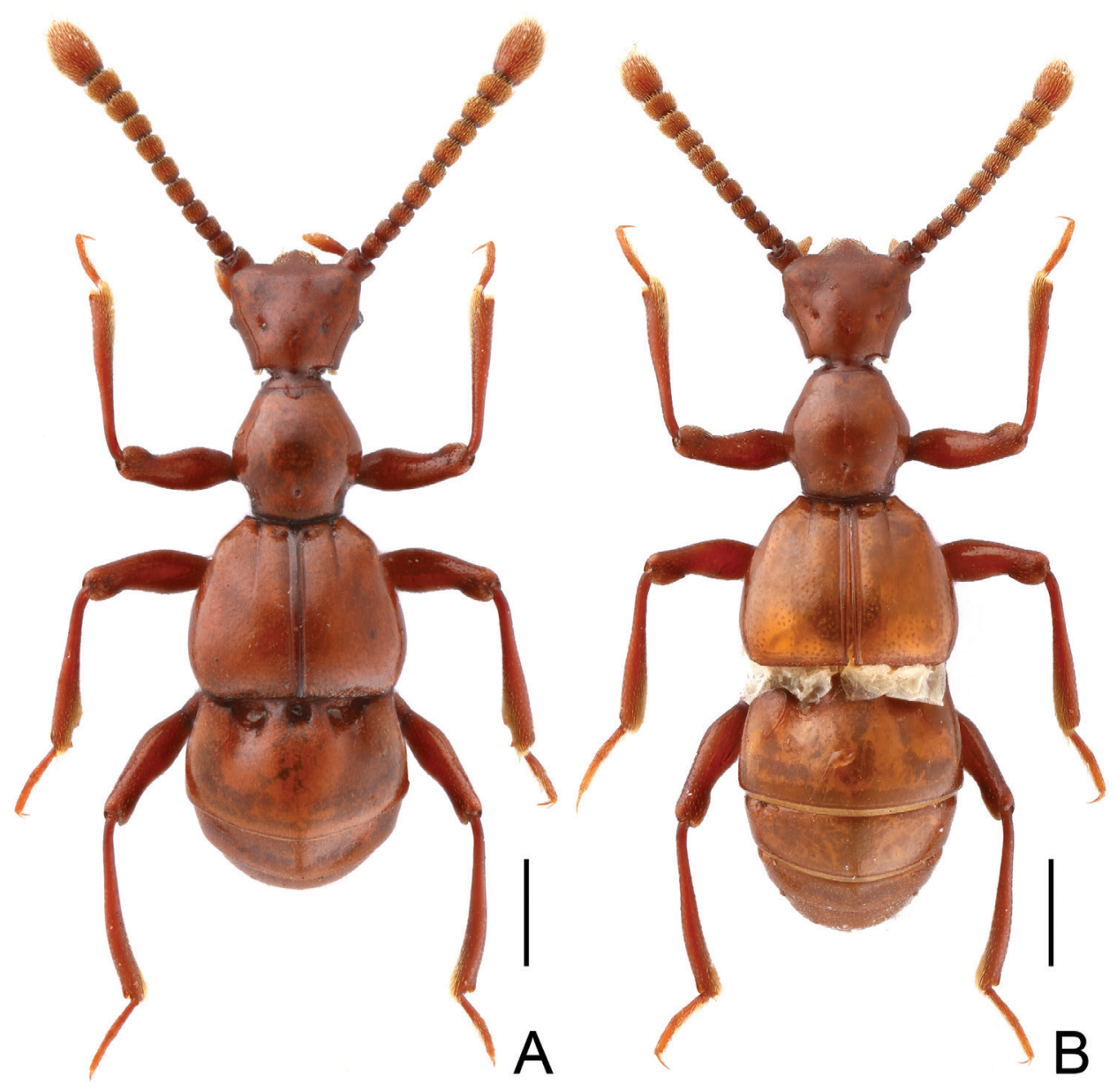

Figure I. Dorsal habitus of Tangius indicus. A male B female. Scales (mm): 0.5.

indicus sp. n., det. Yin \& Li 2013, MHNG'. Paratypes: INDIA: $4 \hat{\jmath} \widehat{\partial}, 3$ $q$ q , same

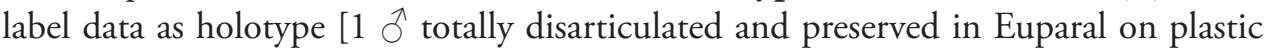
boards; $1 \hat{\jmath}$ with left antenna and abdomen missing]; 1 ㅇ, labeled 'INDIA: Darjeeling, distr., 13 km N. Ghoom, 1500 m, 15.X.1978, I. Löbl, Bes. nr. 15, litter'. Each paratype bear a type label as 'Paratype [yellow], Tangius indicus sp. n., det. Yin \& Li, 2013, MHNG'.

Description. Male (Fig. 1A). Length 2.91-2.97 mm. Surface almost glabrous. Head trapezoidal, slightly transverse, HL $0.61-0.62 \mathrm{~mm}$, HW $0.64-0.65 \mathrm{~mm}$; clypeus covered with sparse short setae anteriorly; Antennomeres II-X (Fig. 2A) each subcylindrical, apical antennomeres nearly oval, enlarged. Each eye composed of about 35 facets. Pronotum about as long as wide, PL $0.62-0.63 \mathrm{~mm}$, PW $0.61-0.62 \mathrm{~mm}$; roundly expanded at lateral margins; pronotal apex and base narrowed and truncate. Elytra (Fig. 2I) wider than long, EL 0.79-0.81 mm, EW 1.00-1.03 mm; inner two ba- 


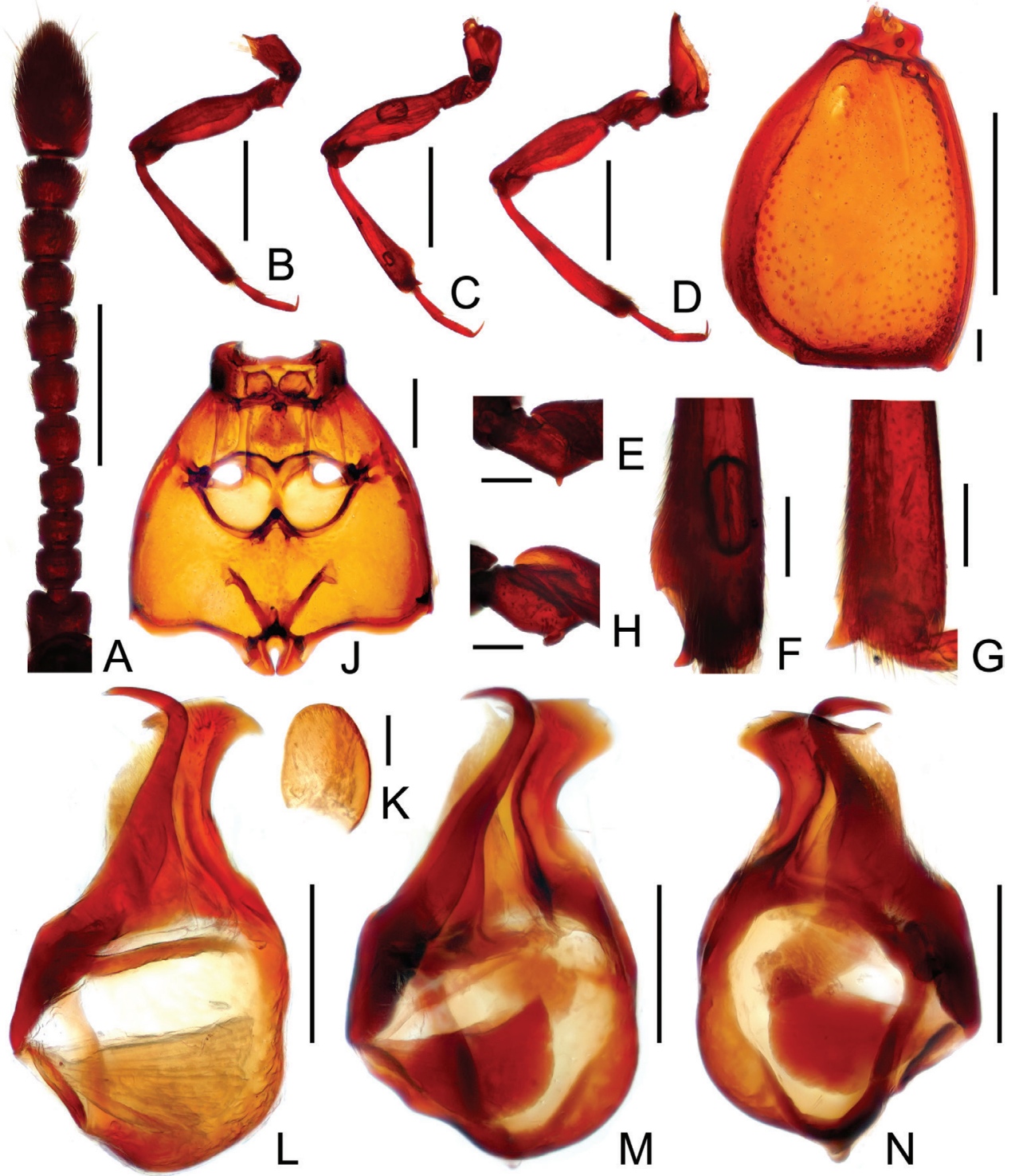

Figure 2. Male diagnostic features of Tangius indicus $(\mathbf{A}-\mathbf{F}, \mathbf{H}-\mathbf{K}, \mathbf{M}-\mathbf{N})$ and T.glabellus $(\mathbf{G}, \mathbf{L})$. A antenna $\mathbf{B}$ fore leg $\mathbf{C}$ mid leg $\mathbf{D}$ hind leg $\mathbf{E}$ protrochanter $\mathbf{F}, \mathbf{G}$ apical portion of mesotibia $\mathbf{H}$ metatrochanter I left elytron J meso- and metaventrites $\mathbf{K}$ sternite IX L, $\mathbf{M}$ aedeagus, in dorsal view $\mathbf{N}$ same, in ventral view. Scales (mm): A, B, C, D, I = 0.5; J, L, M, N = 0.2; E, F, G, H, K = 0.1 .

sal foveae close; discal suture extending to less than half elytral length. Hind wings fully developed. Metaventrite (Fig. 2J) with posterior margin narrowly and deeply notched medially. Protrochanters (Figs 2B, E) with small ventral denticle at middle; mesotibiae (Figs 2C, F) with broadly concave mesal margin before triangular preapical spine; 
metatrochanters (Figs 2D, H) with blunt ventral projection near apex; all femora with ringed sulcus near base. Abdomen slightly wider than long, AL 0.81-0.83 mm, AW 1.03-1.07 mm; sternite IX (Fig. 2K) nearly oval. Aedeagus (Figs 2M, N) length 0.57 $\mathrm{mm}$; median lobe asymmetric, apex rounded, with sharp, weakly-sclerotized projection at right side; dorsal lobe well-sclerotized, slender, curved rightwards near apex.

Female (Fig. 1B). Identical to male except antennomeres shorter, and mesotibiae lacking distal concavity and preapical tooth.. Measurements: BL 2.73-2.81 mm, HL 0.51-0.52 mm, HW 0.53-0.54 mm, PL 0.53-0.54 mm, PW 0.52-0.54 mm, EL 0.66-0.68 mm, EW 1.00-1.03 mm, AL 0.91-0.95 mm, AW 1.06-1.07 mm.

Comparative notes. The new species is closely allied to $T$. glabellus in sharing similar body size, general habitus, including the unusual head shape, and aedeagal structure (Figs 2L, M). Males of these two species can be best separated by the subcylindrical antennomeres VII-X in T. indicus, and the mesotibiae being broadly concave just before the preapical denticle (Fig. 2G), while T. glabellus has asymmetric, transversely trapezoidal antennomeres VII-X, and the mesotibiae with straight mesal margins (Fig. 2G). The females of $T$. indicus have relatively longer antennomeres than those of female $T$. glabellus.

Distribution. North India: Meghalaya, West Bengal.

Biology. One female paratype was collected from sifted litter, as inferred from the label data. Members of this genus are supposed to be inquilines of ants as they exhibit obvious morphological adaptions to myrmecophily, e.g. smooth body surface, compressed antennae, reduction of foveae, etc. The type series of T. glabellus was collected from the colony of an unidentified ant nesting under a fallen tree.

Etymology. The specific epithet refers to the country where the type series were collected.

\section{Acknowledgements}

The first author thanks Giulio Cuccodoro (Geneva, Switzerland) for providing access to the pselaphine collection during the author's one-month visit at the museum. Two anonymous reviewers critically commented on a previous version of the manuscript. The present study is supported by the National Science Foundation of China (No. 31172134), Shanghai Normal University (Sk201242), and East China Normal University (Fund for Overseas Training, International Meeting and Domestic Visit).

\section{References}

Yin ZW, Li LZ, Zhao MJ (2012) Contributions to the knowledge of the myrmecophilous pselaphines (Coleoptera, Staphylinidae, Pselaphinae) from China. I. Tangius glabellus gen. et sp. nov. from Tibet. Zootaxa 3397: 55-61. 